\title{
Investigation of blade performance of horizontal axis wind turbine based on blade element momentum theory (BEMT) using NACA airfoils
}

\author{
Nitin Tenguria $^{1}$, N.D. Mittal ${ }^{1}$, Siraj Ahmed ${ }^{2}$ \\ ${ }^{1}$ Department of Applied Mechanics, Maulana Azad National Institute of Technology, Bhopal, INDIA \\ ${ }^{2}$ Department of Mechanical Engineering, Maulana Azad National Institute of Technology, Bhopal, INDIA \\ Corresponding Author: e-mail: nitintenguria@yahoo.co.in, Tel +91-9827354261
}

\begin{abstract}
The basic principle of wind turbine converting wind energy into electricity comes from the lift produced by the air flowing through the rotor. The shape of rotor blade plays an important role in determining the overall aerodynamic performance of a horizontal axis wind turbine. In this work, blade is designed for a $5 \mathrm{KW}$ horizontal axis wind turbine which is already in market. For designing blade, blade element momentum theory (BEMT) is used and a computer program is developed to automate the complete procedure. Two NACA airfoils are taken for the comparative calculation of elemental power coefficient and other parameters such as chord, thickness and twist distribution. The airfoil taken for designing the blade is same from root to tip. Stresses are maximum at the blade root. In this work, the blade root is thickest portion of the blade and twist is maintained such that the angle of attack will be maximum at every station of the blade. In the designed blade, the elemental power coefficient is maximum in transition segment. The present method is useful for predicting the performance of wind turbine blade.
\end{abstract}

Keywords: Power coefficient, Twist, Chord, Airfoil, Design.

\section{Introduction}

The power efficiency of wind energy systems has a high impact in the economic analysis of this kind of renewable energies. The efficiency in these systems depends on many subsystems: blades, gearbox, electric generator and control. Some factors involved in blade efficiency are the wind features, like its probabilistic distribution, the mechanical interaction of blade with the electric generator, and the strategies dealing with pitch and rotational speed control. It is a complex problem involving many factors, relations and constraints. The increasing awareness of the general public to climate change and global warming has provided opportunities for wind turbine applications in the UK. The UK claims $40 \%$ of the wind energy resources of Europe. Study of Ackermann, (2002) shows Europe leads the world with $70.3 \%$ (23GW peak) of the total operational wind power capacity world wide. As well as large wind turbines operating in open areas on- and off-shore, more small-scale wind turbines are being installed and operated by homeowners and small enterprises.

One of the differences between large- and small-scale wind turbines is that small-scale wind turbines are generally located where the power is required, often within a built environment, rather than where the wind is most favorable. In such location, the wind is normally weak, turbulent and unstable in terms of direction and speed, because of the presence of buildings and other adjacent obstructions. To yield a reasonable power output from a small-scale wind turbine located in this turbulent environment, and to justify such an installation economically, the turbines have to improve their energy capture, particularly at low wind speeds and be responsive to changes in wind direction. This means that small-scale turbines need to be specifically designed to work effectively in low and turbulent wind resource areas.

According to Spera, (1994) the Glauert and Wilson methods were mostly used for blade design. The objectives of these methods were to obtain the maximum power coefficient of each blade section at the design wind speed. Because the time variation characteristics of wind speed are not taken into account, blades designed by these methods cannot achieve the maximum annual energy output. Furthermore, design results from these methods must be substantially amended to get smooth chord length and twist 
distributions. Because the amended results already deviate from the design points, effectively controlling design results pose problems.

A resent study by Maalawi et al, (2001) has indicated that the theoretical optimum distribution of the inflow angle can be adequately determined from an exact trigonometric function method, which is based on Glauert's, (1935) optimum condition. The developed approach eliminated much of the numerical efforts as required by the other iterative procedures, and a unique relation in the angle of attack was developed, ensuing convergence of the attained solutions. A prototype $3 \mathrm{~kW}$ horizontal upwind type wind turbine generator of $4 \mathrm{~m}$ in diameter has been designed by Nagai et al. (2009) and examined under real wind conditions. The machine was designed based on the concept that even small wind turbines should have a variable pitch control system just as large wind turbines, especially in Japan where typhoons occur at least once a year. A characteristic of the machine is the use of a worm and gear system with a stepping motor installed in the center of the hub, and the rotational main shaft. The machine is constructed with no mechanical breaking system so as to avoid damage from strong wind. In a storm, the wind turbine is slowed down by adjusting the pitch angle and the maximum electrical load. Usually, the machine is controlled at several stages depending on the rotational speed of the blades. Two control methods have been applied: the variable pitch angle, and regulation of the generator field current. The characteristics of the generator under each rotational speed and field current are first investigated in the laboratory. This paper describes the performances of the wind turbine in terms of the functions of wind turbine rotational speed, generated outputs, and its stability for wind speed changes. The expected performances of the machine have been confirmed under real wind conditions and compared with numerical simulation results. The wind turbine showed a power coefficient of 0.257 under the average wind speed of $7.3 \mathrm{~m} / \mathrm{s}$.

An optimization model presented by Liu et al. (2007) for horizontal axis wind turbine. The model refers to the wind speed distribution function on the specific wind site, with an objective to satisfy the maximum annual energy output. To speedup the research process and guarantee a global optimal result, the extended compact genetic algorithm (ECGA) is used to carry out the search process. Compared with simple genetic algorithm, ECGA runs much faster and can get more accurate results with a much smaller population size and fewer function evaluations. Using the developed optimization program, blades of $1.3 \mathrm{MW}$ stall regulated wind turbine are designed. Compared with the existing blades, the designed blades have obviously better aerodynamic performance. The design and selection procedure of airfoil sections for small wind turbine blades is discussed and implemented by Habali, (1995). It is found that for blades up to $5 \mathrm{~m}$. long, two different airfoils mixed at the outer third of the span will be sufficient and have demonstrated good strength and aerodynamic characteristics.

A mathematical model for fluid dynamics wind turbine design by Lanzafame et al., (2007) (based on blade element momentum theory) has been implemented and improved. The mathematical simulations have been compared with experimental data found in literature. The simulation was performed for the whole wind velocity range, in on-design and off-design conditions. Several simulations were performed in order to maximize the agreement between the simulated and experimental data. Particular attention was paid to the tangential induction factor and to the models for the representation of the lift and drag coefficients.

Several researchers have contributed to the insight into rotor design. Snel $(1998,2003)$ describe wind turbine aerodynamics in general and gives an overview of the available methods to compute the aerodynamic rotor performance. Fuglsang, (2002) describes the methods needed in the rotor design process in terms of a guideline and Tangler, (2000) gives a short historical overview of the rotor design investigations. Also, aerodynamic optimization of rotors is described by Fuglsang, (1999) Giguere, (2000) Nygaard, (1999) respectively. Details in rotor design to increase the power efficiency have been investigated by several researchers; Johansen and Madsen (2007) investigated especially the root part of rotors and found that a new root design of the rotors did not increase the power performance significantly. However, the interaction between different parameters in the rotor design, such as Tip- Speed-Ratio, Reynolds number etc. still needs to be investigated simultaneously when addressing design of rotors with maximum power performance.

This paper focuses on performance investigation of wind turbine blade for a 5KW HAWT. This work is carried out on a commercial available wind turbine manufactured by Qingdao Sea.Silkroad Int'l Co.Ltd. all through this work, the lift coefficient is taken as 1.1 which is constant throughout the blade. The lift and drag coefficients are taken from Abbott, (1958). These values are taken for Reynolds number $3 \times 10^{6}$. Under this investigation, two airfoils are taken, namely, the four digits and the five digit airfoil. The blade is divided into ten elements and power coefficient is calculated for each element with the help of a computer program. Chord and thickness of the blade is maximum at the root because of stresses and the twist is maximum near the root. Figure 1 shows the complete process of the work.

\section{Specification and Airfoil Properties}

\subsection{Specifications}

Table 1: The specification of wind turbine taken, are made by Qingdao Sea.Silkroad Int'l Co.Ltd. The capacity of this turbine is $5 \mathrm{KW}$.

\begin{tabular}{|l|l|}
\hline Model & HY-5KW \\
\hline Rated power(kw) & 5 \\
\hline Maximum power(kw) & 5.4 \\
\hline
\end{tabular}


Table 1 (cont'd): The specification of wind turbine taken, are made by Qingdao Sea.Silkroad Int'l Co.Ltd. The capacity of this turbine is $5 \mathrm{KW}$.

\begin{tabular}{|l|l|}
\hline Rotor Diameter & 5.6 \\
\hline Rated voltage( $(\mathrm{V})$ & DC240V/AC220 \\
\hline Rated wind speed $(\mathrm{m} / \mathrm{s})$ & 11 \\
\hline Starting Wind speed $(\mathrm{m} / \mathrm{s})$ & 3 \\
\hline Working wind speed $(\mathrm{m} / \mathrm{s})$ & $4-25$ \\
\hline Survived wind speed(m/s) & 50 \\
\hline Blades materials & Fiberglass-reinforced plastics \\
\hline Rated rotate speed(r/min) & 240 \\
\hline Speed regulation method & Yawing \& Electromagnetic brake \\
\hline Generator style & 3 -phase AC PM \\
\hline Tower height $(\mathrm{m})$ & 6 \\
\hline Stop method & By hand \\
\hline main machine weight $(\mathrm{kg})$ & 340 \\
\hline Guyed tower weight $(\mathrm{kg})$ & 350 \\
\hline Free standing tower weight $(\mathrm{kg})$ & 360 \\
\hline
\end{tabular}

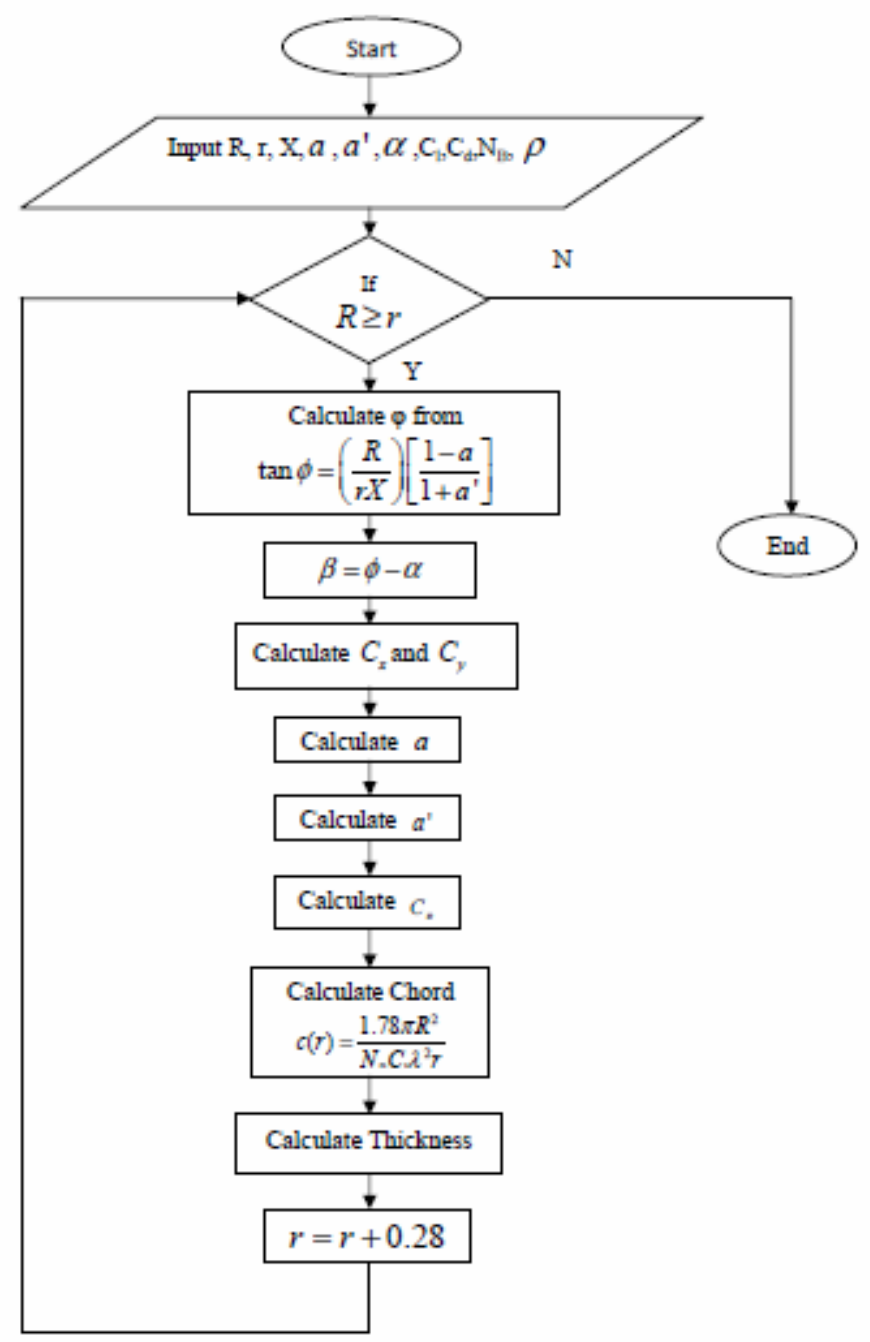

Figure1: General program flowchart 


\subsection{Airfoil Properties}

In this work, two airfoils are taken, one of them is four digit and the other is five digit airfoil. Theory of wing section by Abbott, (1958) is used for taking the properties of airfoils. The selection of airfoil is very important point in designing an efficient rotor. Grifith, (1977) showed that the output power is greatly affected by the airfoil lift-to-drag ratio, while Hassanein, (2000) recommended that the airfoil be selected according to its location along the blade to ensure its highest contribution to the overall performance. The numbering system for NACA wing sections of the four-digit series is based on the section geometry. The first integer indicates the maximum value of the mean-line ordinate $y_{c}$ in per cent of the chord. The second integer indicates the distance from the leading edge to the location of the maximum camber in tenths of the chord. The last two integers indicate the section thickness in per cent of the chord. Thus the NACA 4412 wing section has 4 per cent camber at 0.4 of the chord from the leading edge and is 12 per cent thick. The numbering system for wing sections of the NACA five-digit $\left(64_{3}-218\right)$ series is based on a combination of theoretical aerodynamic characteristics and geometric characteristics. The first integer indicates the amount of camber in terms of the relative magnitude of the design lift coefficient; the design lift coefficient in tenths is thus three-halves of the first integer. The second and third integers together indicate the distance from the leading edge to the location of the maximum camber; this distance in per cent of the chord is one-half the number represented by these integers. The last two integers indicate the section thickness in per cent of the chord.

\section{The Blade Element - Momentum (BEM) Theory}

The basic assumption in blade element momentum theory is that the force of the blade element is solely responsible for the change of momentum in the air which passes through the annulus swept by the blade element. It is therefore to be assumed that there is no radial interaction between the flows through contiguous annuli - a condition that is strictly only true if the axial flow induction factor does not vary radially. In practice, the axial flow induction factor is seldom uniform but experimental examination of flow through propeller disk by lock (1924) shows that the assumption of the radial independence is acceptable. The component of aerodynamic force on $\mathrm{N}$ blade elements resolved in the axial direction is

$$
\delta L \cos \phi+\delta D \sin \phi=\frac{1}{2} \rho W^{2} N c\left(C_{L} \cos \phi+C_{d} \sin \phi\right) \delta r
$$

The rate of change of axial momentum of the air passing through the swept annulus is

$$
\rho V_{0}(1-a) 2 \pi r \delta r 2 a V_{0}=4 \pi \rho V_{0}^{2} a(1-a) r \delta r
$$

The drop in wake pressure caused by wake rotation is equal to the increase in dynamic head, which is

$$
\frac{1}{2} \rho(2 a \Omega r)^{2}
$$

Therefore, the additional axial force on the annulus is

$$
\frac{1}{2} \rho\left(2 a^{\prime} \Omega r\right)^{2} 2 \pi r \delta r
$$

Thus,

$$
\frac{1}{2} \rho W^{2} N_{c}\left(C_{l} \cos \phi+C_{d} \sin \phi\right) \delta r=4 \pi \rho\left[V_{0}^{2} a(1-a)+\left(a^{\prime} \Omega r\right)^{2}\right] r \delta r
$$

Simplifying,

$$
\frac{W^{2}}{V_{0}^{2}} N \frac{C}{R}\left(C_{l} \cos \phi+C_{d} \sin \phi\right)=8 \pi\left(a(1-a)+\left(a^{\prime} \lambda \mu\right)^{2}\right) \mu
$$

The element of axial rotor torque caused by aerodynamic forces on the blade elements is

$$
(\delta L \sin \phi-\delta D \cos \phi) r=\frac{1}{2} \rho W^{2} N c\left(C_{l} \sin \phi-C_{d} \cos \phi\right) r \delta r
$$

The rate of change of angular momentum of the air passing through the annulus is

$$
\rho V_{0}(1-a) \Omega r 2 a^{\prime} r 2 \pi r \delta r=4 \pi \rho V_{0}(\Omega r) a^{\prime}(1-a) r^{2} \delta r
$$

Equating the two moments

$$
\frac{1}{2} \rho W^{2} N c\left(C_{l} \sin \phi-C_{d} \cos \phi\right) r \delta r=4 \pi \rho V_{0}(\Omega r) a^{\prime}(1-a) r^{2} \delta r
$$

Simplifying, 


$$
\frac{W^{2}}{V_{0}^{2}} N \frac{c}{R}\left(C_{l} \sin \phi-C_{d} \cos \phi\right)=8 \pi \lambda \mu^{2} a^{\prime}(1-a)
$$

Where the parameter

$$
\mu=\frac{r}{R}
$$

It is convenient to put

And

$$
C_{x}=C_{l} \cos \phi+C_{d} \sin \phi
$$

$$
C_{y}=C_{l} \sin \phi-C_{d} \cos \phi
$$

Solving Eqns. (3) and (7) to obtain values for the flow induction factors $a$ and $a^{\prime}$ using two-dimensional aerofoil characteristics requires an iterative process. The following equations, derived from Eqs. (3) and (7), are convenient in which the right-hand sides are evaluated using existing values of the flow induction factors yielding simple equations for the next iteration of the flow induction factors.

$$
\begin{aligned}
\frac{a}{1-a} & =\frac{\sigma_{r}}{4 \sin ^{2} \phi}\left[C_{x}-\frac{\sigma_{r}}{4 \sin ^{2} \phi} C_{y}^{2}\right] \\
\frac{a^{\prime}}{1+a^{\prime}} & =\frac{\sigma_{r} C_{y}}{4 \sin \phi \cos \phi}
\end{aligned}
$$

Blade solidity $\sigma$ is defined as total blade area divided by the rotor disc area and is a primary parameter in determining rotor performance. Chord solidity $\sigma_{r}$ is defined as the total blade chord length at a given radius divided by the circumferential length at that radius.

$$
\sigma_{r}=\frac{N c}{2 \pi r}=\frac{N C}{2 \pi \mu R}
$$

It is argued by Wilson and Lissaman (1974) that the drag coefficient should not be included in Eqs. (8) and (9) because the velocity deficit caused by drag is confined to the narrow wake which flows from the trailing edge of the aerofoil. Furthermore, Wilson and Lissaman reason, the drag-based velocity deficit is only a feature of the wake and does not contribute to the velocity deficit upstream of the rotor disc. The basis of the argument for excluding drag in the determination of the flow induction factors is that, for attached flow, drag is caused only by skin friction and does not affect the pressure drop across the rotor. Clearly, in stalled flow the drag is overwhelmingly caused by pressure. In attached flow it has been shown by Young and Squire (1938) that the modification to the inviscid pressure distribution around an aerofoil caused by the boundary layer has an affect both on lift and drag. The ratio of pressure drag to total drag at zero angle of attack is approximately the same as the thickness to chord ratio of the aerofoil and increases as the angle of attack increases.

One last point about the BEM theory: the theory is strictly only applicable if the blades have uniform circulation, i.e., if $a$ is uniform. For non-uniform circulation there is a radial interaction and exchange of momentum between flows through adjacent elemental annular rings. It cannot be stated that the only axial force acting on the flow through a given annular ring is that due to the pressure drop across the disc. However, in practice, it appears that the error involved in relaxing the above constraint is small for tip speed ratios greater than 3 .

The complete procedure can be written as:

(i) Guess $a$ and $a^{\prime}\left(a=a^{\prime}=0\right.$ is acceptable to start Hau (2006));

(ii) Calculate $\phi$ form

$$
\tan \phi=\left(\frac{R}{r X}\right)\left[\frac{1-a}{1+a^{\prime}}\right]
$$

(iii) Calculate $\alpha$ from $\alpha=\phi-\beta$;

(iv) Calculate $C_{l}$ and $C_{d}$ from graph and table;

(v) Calculate $C_{x}$ and $C_{y}$ from

$$
\begin{aligned}
& C_{x}=C_{l} \cos \phi+C_{d} \sin \phi \\
& C_{y}=C_{l} \sin \phi-C_{d} \cos \phi
\end{aligned}
$$


(vi) Calculate $a$ from

$$
\frac{a}{1-a}=\frac{\sigma_{r}}{4 \sin ^{2} \phi}\left[C_{x}-\frac{\sigma_{r}}{4 \sin ^{2} \phi} C_{y}^{2}\right]
$$

(vii)Calculate $a^{\prime}$ from

$$
\frac{a^{\prime}}{1+a^{\prime}}=\frac{\sigma_{r} C_{y}}{4 \sin \phi \cos \phi}
$$

(viii) Calculate $C_{p}$ from

$$
C_{p}=4 a(1-a)^{2}
$$

(ix) Go to step (ii)

These equations are solved iteratively because of the dependency between $a, a^{\prime}, C_{x}, C_{y}, \phi$ and $\sigma$.

\section{Results and Discussion}

In this work, the blade is divided into ten elements and all parameters such as chord, thickness, twist and power coefficient are calculated on these elements.

\subsection{Chord and Thickness Distribution}

A chord direction is perpendicular to the span direction and lies in the plane extending through the leading edge and the trailing edge. A shoulder is the point where chord is maximum and it is minimum at the tip of the blade. Stresses are maximum at the blade root so that the blade root is the thickest portion of the blade. The thickness distribution is calculated in terms of the chord where the total thickness of the blade at any station will be a percentage of the chord length at that station. Figure 2 shows the chord distribution for four and five digit airfoils. Figure 3 and Figure 4 show the thickness distribution. Both chord and thickness are reducing from root to tip. The chord is calculated on the concept used by Ryu (2004).

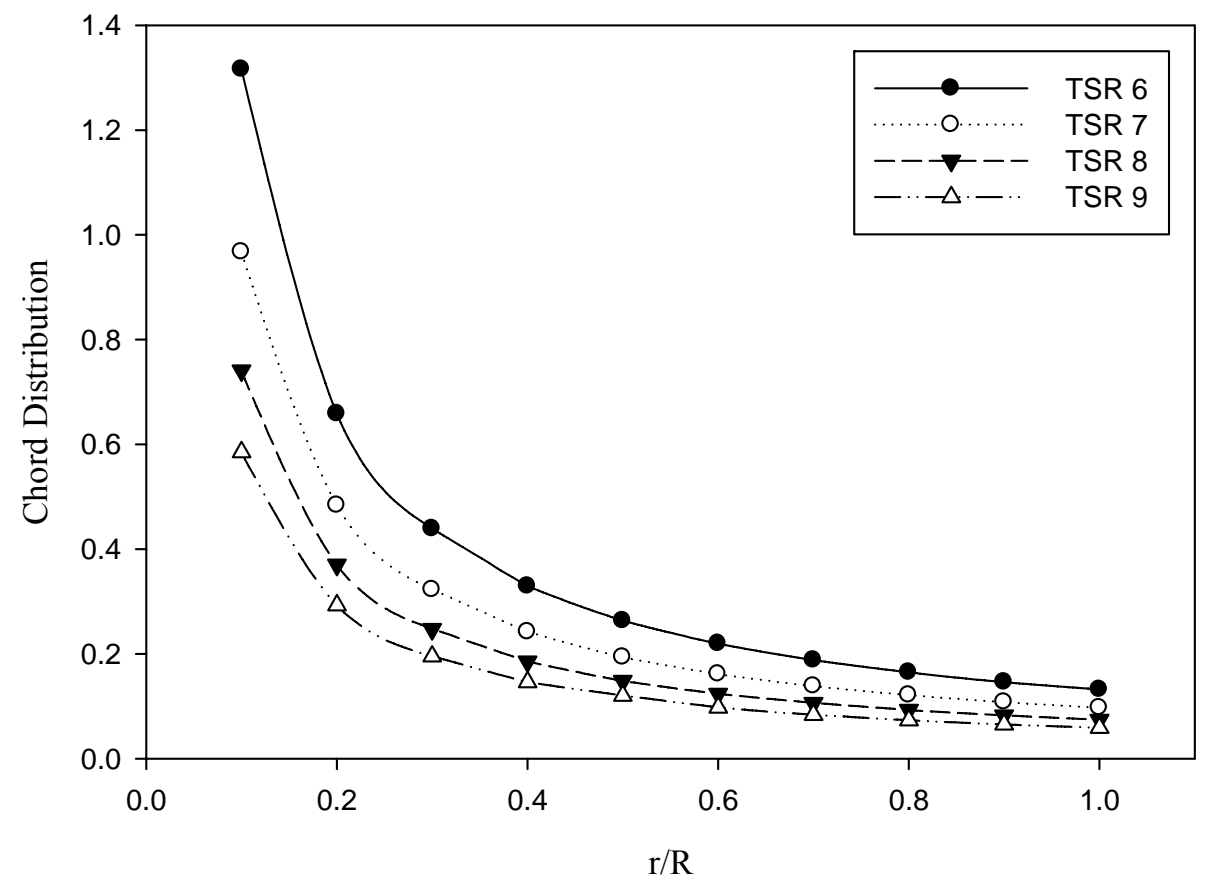

Figure 2: Chord distribution for four (NACA 4412) and five digit (NACA64 3 -218) airfoil 


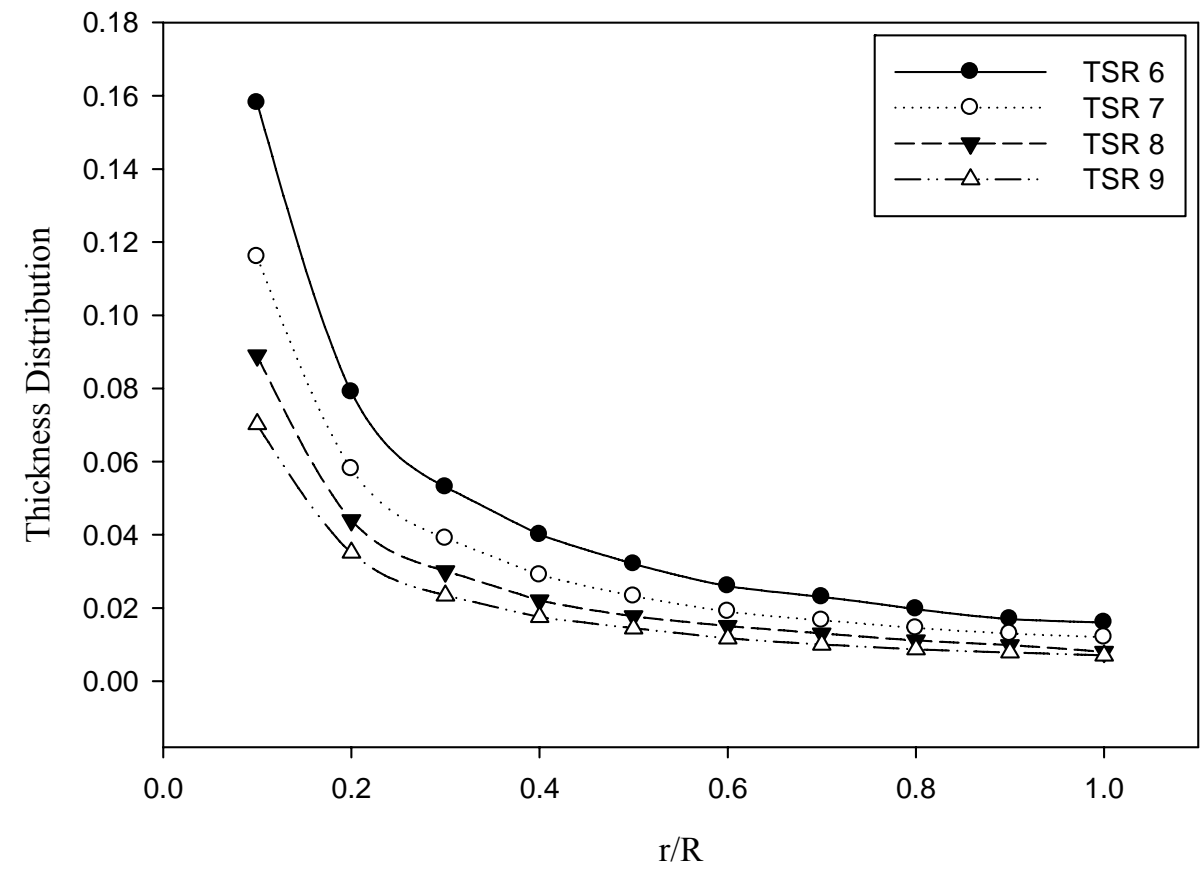

Figure 3: Thickness distribution for four digit (NACA 4412) airfoil

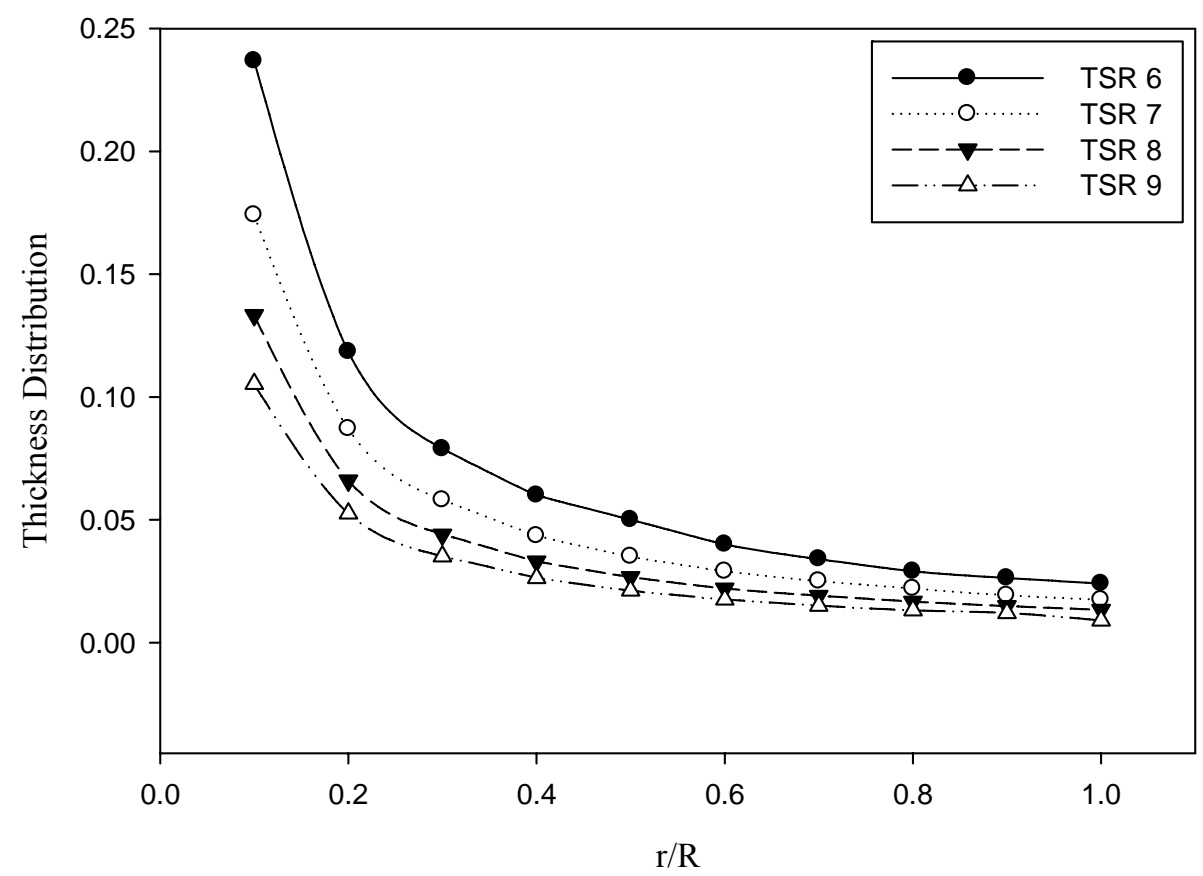

Figure 4: Thickness distribution for four digit (NACA 4412) airfoil

\subsection{Twist Distribution}

The twist of a wind turbine blade is defined in terms of the chord line. It is a synonym for the pitch angle. However, the twist defines the pitch settings at each station along the blade according to the local flow conditions. The pitch angle ( $\beta$ ) is large near the root (where local speeds are low), and small at the tip (where local speeds are high). The apparent wind angle changes along the blade due to the increase in blade speed with increasing distance outboard. Hence, to maintain optimum angle of attack of the blade section to the wind, it must be twisted along its length. In this work, the twist distribution is maintained such that the lift 
coefficient will be maximum at every station Hau (2006). Figure 5 and Figure 6 give the twist distribution for four and five digit airfoils. The twist distributions are calculated for different tip speed ratios.

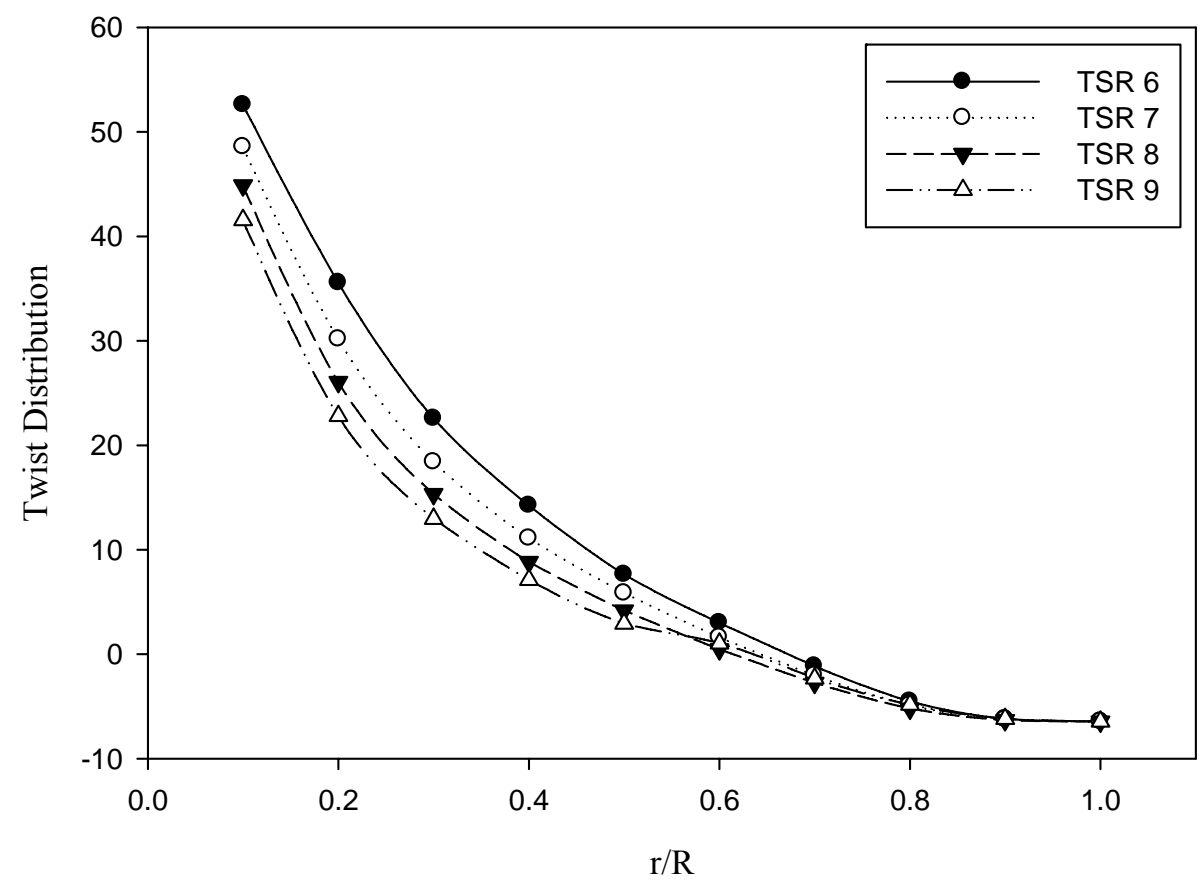

Figure 5: Twist distribution for four digit (NACA 4412) airfoil

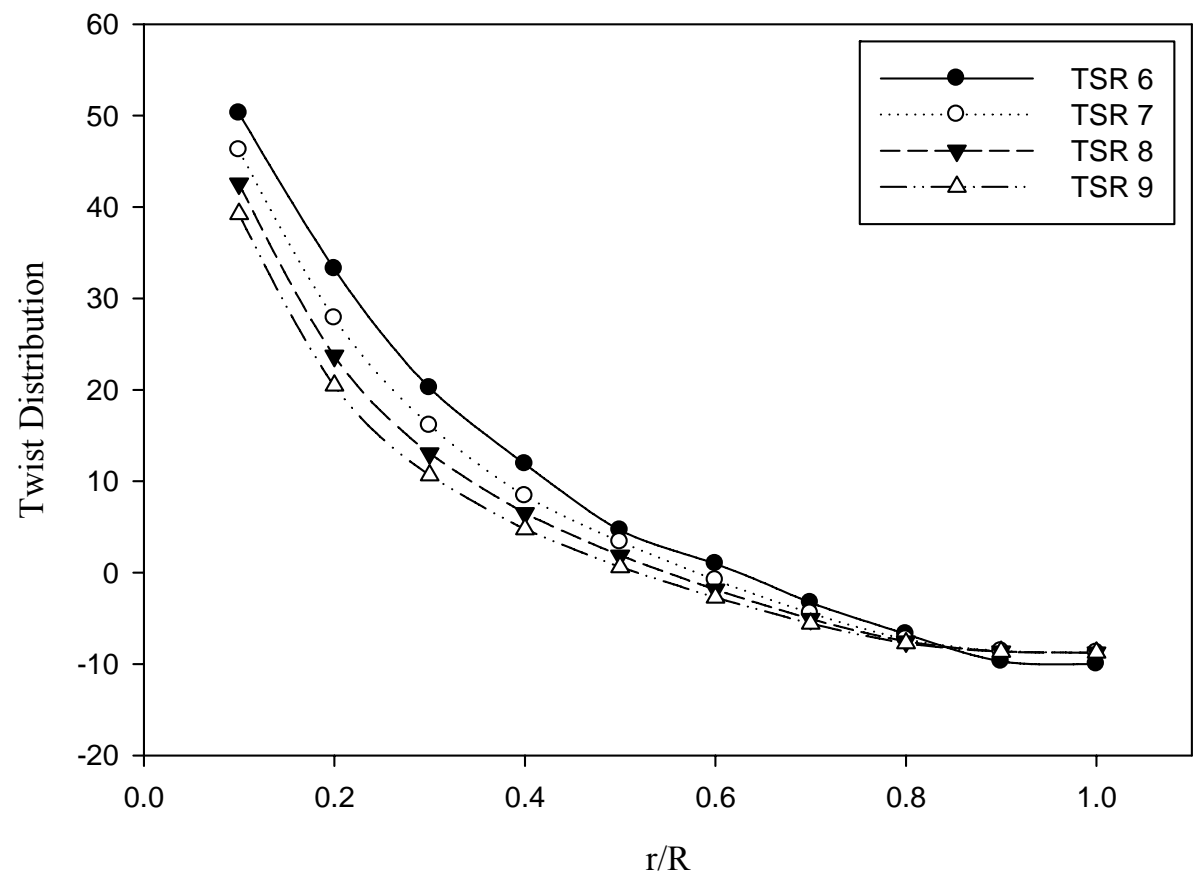

Figure 6: Twist distribution for five (NACA64 $\left.{ }_{3}-218\right)$ digit airfoil 


\subsection{Power Coefficient}

In this paper, elemental power coefficient is calculated at elements of the blade based on blade element momentum theory. The lift coefficient is constant throughout the blade for both airfoils. The ratio of $\mathrm{C}_{1} / \mathrm{C}_{\mathrm{d}}$ is 108.91 for four digit airfoil and 71.9 for five digit airfoil respectively. The Figure 7 and Figure 8 show the elemental power coefficient for four and five digit airfoils respectively at four different tip speed ratios based on blade element momentum theory given in Hau, (2006).

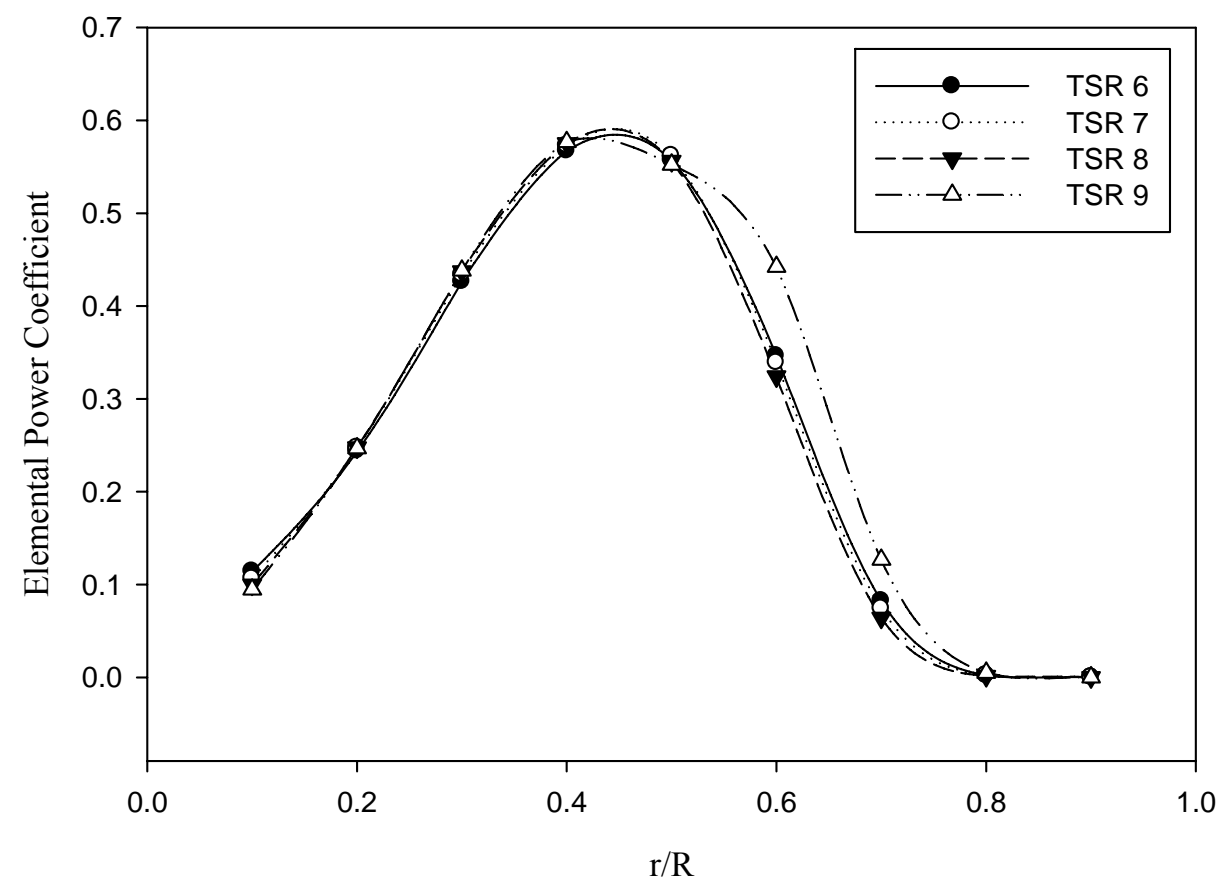

Figure 7: Elemental power coefficient for four digit (NACA 4412) airfoil

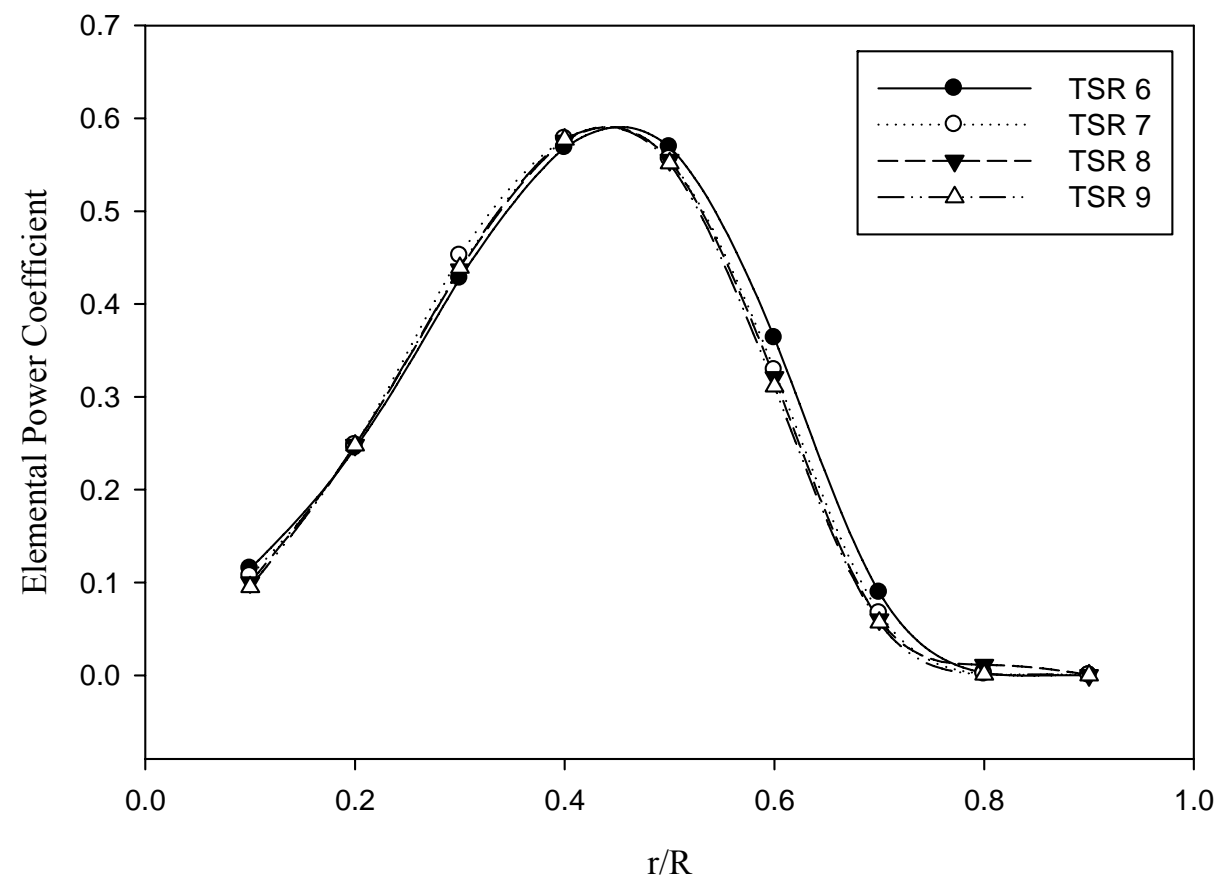

Figure 8: Elemental power coefficient for five digit (NACA64 $\left.{ }_{3}-218\right)$ airfoil 


\section{Conclusion}

This paper presents the investigation of blade performance for a $5 \mathrm{KW}$ horizontal axis wind turbine based on blade element momentum theory. The most difficult issues for the BEM theory are: mathematical representation of the correct lift and drag coefficient values and correct evaluation of the axial and tangential induction factors. The blades having constant lift to drag ratio corresponding to all elements are investigated. Two NACA airfoils are taken in this work (the four digit one and the five digit one). For the selected airfoils and the blade number, the chord, thickness and twist decrease as we move from root to tip. At the blade root, chord and thickness attain their maximum values. Twist is maintained in such a manner that the angle of attack gives the maximum lift coefficient. Chord distribution is same for both airfoils at all tip speed ratios. Twist distribution is different in both airfoils at different tip speed ratios. The value of elemental power coefficient is maximum for elements where $\mathrm{r} / \mathrm{R}$ varies from 0.3 to 0.6. The nature of the flow pattern around an aerofoil is determined by the Reynolds number and this significantly affects the values of the lift and drag coefficients. The power coefficient of a rotor varies with the tip speed ratio (the ratio of rotor tip speed to free wind speed) and is only a maximum for a unique tip speed ratio. The maximum power coefficient that can be achieved in the presence of drag is significantly less than the Betz limit at all tip speed ratios. Drag reduces the power coefficient at high tip speed ratios. Structural and CFD analysis of the designed blade can also be done.

\section{Nomenclature}

a Axial interference factor

$a^{\prime} \quad$ Rotational interference factor

$B \quad$ Number of blades

c Chord

$r \quad$ Radius of blade element or point on blade

$R \quad$ Blade tip radius

$W \quad$ Wind velocity relative to a point on rotating blade

$C_{l} \quad$ Section lift coefficient

$C_{d} \quad$ Section drag coefficient

$C_{x} \quad$ Coefficient of sectional blade element force normal to the rotor plane

$C_{y} \quad$ Coefficient of sectional blade element force parallel to the rotor plane

$C_{p} \quad$ Power coefficient

$\rho \quad$ Air density

$\sigma_{r} \quad$ Rotor solidity

$\Omega \quad$ Rotational speed of rotor

$\lambda \quad$ Tip speed ratio

$\alpha \quad$ Blade segment angle of attack

$\theta \quad$ Angle of blade chord with rotor plane

$\phi \quad$ Angle of relative wind from rotor plane

\section{References}

Abbott I.H. and Vonoenhoff 1958. AET. In: Theory of wing sections. Ince NY: Dover.

Ackermann T. Soder,L. 2002. An overview of wind energy-status 2002. Renew. Sustain Energy Rev., Vol. 6 pp.67-128.

Fuglsang P. L. and Madsen H. A. (1999). Optimization Method for Wind Turbine Rotors. Journal of Wind Engineering and Industrial Aerodynamics. Vol. 80. pp. 191-206.

Fuglsang P. 1. 2002. Aerodynamic design guidelines for wind turbine rotors. In: CD-Rom proceedings, Vol. 4. GRACM congress on computational mechanics, Patras (GR), 27-29 J. T.sahalis, D.T. (ed.).

Giguere, P and Selig M. S. 2000. Blade Geometry Optimization for the Design of Wind Turbine Rotors. 2000 ASME Wind Energy Symposium, Reno NV.

Glauert H. 1935. Durand WF editor. Aerodynamic theory, Vol. IV, Division L. Airplane propellers, chapter XI. Berlin.. pp. 324330.

Griffiths R.T. 1977. The effect of airfoil characteristics on windmill performance. Aeronautical Journal. Vol. 81, No. 7, pp. 322-6.

Habali S.M. 1995. Designing and testing of small mixed airfoil wind turbine blades. J. Renewable Energy, Vol. 61-195.

Hassanein A, El-Banna H, Abdel-Rahman M. 2000. Effectiveness of airfoil aerodynamic characteristics on wind turbine design performance. In: Proceeding of Seventh International Conference on Energy and environment, Vol. I, Cairo, Egypt, March. pp. 525-537. 
Hau. E. 2006. Wind turbines fundamental, technologies, application, economics. Krailling, Springer.

Johansen J., Madsen H.A., Gaunaa, M., Bak, C. 2007. 3D Navier-Stokes Simulations of a rotor designed for Maximum Aerodynamic Efficiency 45. AIAA Aerospace Sciences Meeting and Exhibit, Reno. NV. 8-11

Lanzafame R., M. Messina 2007. Fluid dynamics wind turbine design: Critical analysis, optimization and application of BEM theory. J. Renewable Energy. Vol. 32, pp. 2291-2305.

Liu X., Yan C., Zhiquan. Y. 2007. Optimization model for rotor blades of horizontal axis wind turbine.Front. Mech. Eng. China. Vol. 2, No. 4, pp. 483-488.

Lock C. N. H. 1924. Experiments to verify the independence of the elements of an airscrew blade. ARCR R\&M No. 953.

Maalawi K.Y, Badawy MTSA 2001. Direct method for evaluating performance of horizontal axis wind turbines. Renewable and sustainable Energy Review, Vol. 5, pp. 175-190.

Madsen H.A., Mikkelsen R., Johansen J., Bak, C., Øye, S., Sørensen, N.N. 2005. Inboard rotor/blade aerodynamics and its influence on blade design. In: Bak, C. (ed.), Research in Aeroelasticity EFP. Risø-R-1559(EN).

Nagai B.M., Ameku K. and Roy J.N., 2009. Performance of a $3 \mathrm{~kW}$ wind turbine generator with variable pitch control system, Applied Energy, Vol. 86, No. 9, pp. 1774-1782.

Nygaard T. A. 1999. Optimization of wind turbine rotors, doctoral thesis, Norwegian University of Science and Technology. ISBN 82-471-0472-5.

Ryu J.Y. and D. H. Kim. 2004 Blade design of a 360 KW Direct drive wind turbine generator system. Proceeding of ACCM4, Sydney.

Snel, H. 2003. Review of aerodynamics for wind turbines. Wind Energy, Vol. 6, pp. 203-211.

Snel H. 1988. Review of the present status of rotor aerodynamics, Wind Energy, Vol. 1, pp. 46-69.

Spera D. A. 1994. Wind Turbine Technology. New York: ASME Press.

Tangler J., 2000.The evolution of rotor and blade design, NREL/CP-500-28410. Presented at the American Wind Energy Association Wind Power, Palm Springs, California, April 30.May 4

Wilson R. E. and Lissaman. 1974. P. B. S. Applied aerodynamics of wind-power machines. NTIS: PB-238-595, Oregon State University, USA.

Young, A. D. and Squire, H. B. 1838. The Calculation of the Profile Drag of Aerofoils R\&M No. 1838.

Biographical notes

Nitin Tenguria is a research scholar in Department of Applied Mechanics in MANIT Bhopal India and he received his M.Tech. From MANIT Bhopal India

Dr. N.D. Mittal is a Professor in Department of Applied Mechanics in MANIT Bhopal India. He has more than 35 years of experience in teaching and research.

Dr. Siraj Ahmed is a Professor in Department of Applied Mechanics in MANIT Bhopal India. He has more than 25 years of experience in teaching and research.

Received September 2010

Accepted December 2010

Final acceptance in revised form December 2010 